\title{
LAS CARTAS DE UN GENTILHOMBRE DE PLACER: GONZALO DE LIAÑO, "TROMPETA EN ESTA CORTE"*
}

\author{
NIEVES BARANDA \\ UNED \\ "la buffoneria è vita et anima de la corte" (Pietro Aretino)
}

En una carta de 1583 Gonzalo de Liaño le asegura a la Gran Duquesa de Toscana, Bianca Capello: "Solo os digo que yo soy tronpeta en esta corte, que doy boces publicando lo que merecéys y lo que hazéys a todos los cortesanos desta corte y señoras". En el Renacimiento el mundo se había vuelto un poco más pequeño, el coleccionismo, la necesidad de noticias, de novedades, la búsqueda de información

\footnotetext{
* Esta investigación ha sido posible gracias a la financiación del MEC a través de su programa de estancias breves en centros extranjeros. Es un anticipo de la edición que preparo del epistolario. Recibido: 22-02-2009 Aceptado: 13-04-2009
} 
desde lugares alejados era más urgente y Gonzalo de Liaño sirvió a estos propósitos para el rey Felipe II. Trajo o llevó entre Italia y España gallinas “de pelo enrizado", gámbaros o gambas, perros de Irlanda, caballos, ballestas, un leopardo (murió durante el viaje en las proximidades de Barcelona), simientes y bulbos de algunas plantas, aceite medicinal para las muelas, otro para el estómago, fruteros, reliquias, cuadros y otras piezas de arte, piedras preciosas, imágenes de las villas florentinas con sus jardines, y muchos más objetos, documentos y cartas. Además era portador de noticias, relator de chismes, cimentador de famas y difusor de la cultura de unas cortes en otras, dando cuenta de novedades, modas, costumbres, actitudes, protocolos. Su condición de embajador informal y agente real le permitía cumplir con flexibilidad muchas funciones.

No fue un personaje único en este aspecto. Hay que pensar en muchos otros que cumplían cometidos semejantes a lo largo de los difíciles caminos europeos, pero éste de modo excepcional era un enano bufón que nos ha dejado un inestimable epistolario en testimonio de toda esta actividad. El interés de este atractivo y extenso conjunto de cartas, conservado en el Archivio di Stato di Firenze, es múltiple, porque añade información a las estrechas relaciones políticas entre el rey Felipe II y la Toscana, pone fecha y trámites a la adquisición de varias obras de arte italianas hoy en el Escorial, subraya el interés personal del rey español por estos temas a través de su detenido seguimiento, nos da atisbos sobre el complejo mundo de los agentes artísticos y los embajadores informales y not least nos proporciona, a los historiadores de la literatura y la cultura, una de las muestras más extensas y ricas del discurso epistolar bufonesco en la época. ${ }^{1}$

\footnotetext{
1 Sobre el personaje como agente artístico vid. Salvador Salort y Susanne Kubersky-Piredda, “Art Collecting in Philip II's Spain: The Role of Gonzalo de Liaño, King's Dwarf and Gentleman of the Bedchamber: part I" The Burlington Magazine, CXLVIII (2006), pp. 660-665; y parte II en idem, CXLIX (2007), pp. 224-231; como corresponsal bufonesco N. Baranda, "Las epístolas bufonescas de Gonzalo de Liaño a la gran duquesa de toscana", en Actas del XVI Congreso de la Asociación Internacional de Hispanistas, en prensa, artículo al que remito para cuestiones generales sobre el epistolario y su autor.
} 
Efectivamente, basta asomarse siquiera al tema para saber que son muy escasos - y no solo en España - los testimonios directos de bufones del período, si bien se conocen, gracias a fuentes indirectas o literarias, sus gracias y técnicas para provocar la risa o sus relaciones con los poderosos a quienes servían. En este aspecto es muy relevante la correspondencia particular de Felipe II, que alude a ellos en bastantes ocasiones y que los consideraba parte del círculo familiar más estrecho. De hecho, Gonzalo de Liaño aparece citado en esas cartas con los diminutivos afectivos que tanto se empleaban para estas gentes menudas, porque seguramente fuera un enano: "vuestra hermana se hace tahúr de un nuevo juego que ha traído Gonzalillo". ${ }^{2}$ A pesar de ese conocimiento de los personajes y de saber que participaban del gusto por el intercambio epistolar que manifiesta toda la buena sociedad de la época, son escasísimas las piezas que conservamos en España ${ }^{3}$ y en Italia, salvando los excepcionales diarios del bufón Atanasio, que sirvió en la corte de Urbino entre 1539 y 1564, los testimonios directos son igualmente escasos ${ }^{4}$. Frente a esta penuria de las fuentes directas, el conjunto epistolar de Liaño es ciertamente excepcional y sobrepasa cualquiera de los conocidos, al superar la centena de cartas. De ellas, cincuenta y dos son para la Gran Duquesa y el resto para su marido, escritas entre el 18 de enero de 1580 y junio de 1588, si bien las cinco de ese último año están destinadas al Gran Duque Fernando I, ya que Francisco I, su hermano, había muerto

\footnotetext{
2 Su calidad de bufón había sido conjeturada por F. Bouza a partir de estas menciones, vid. Cartas de Felipe II a sus hijas, ed. de F. Bouza, Madrid, Akal, 1998, p. 125.

${ }^{3}$ F. Bouza, edita siete de las conocidas, vid. "La estafeta del bufón: cartas de gente de placer en la España de Velázquez", Madrid: revista de arte, geografía e historia, 2 (1999), pp. 95-124. A estas hay que añadir las doce de Francés o Francesillo de Zúniga, en Curiosidades bibliográficas. Colección escogida de obras raras de amenidad y erudición, Madrid, M. Rivadenayra, 1855 (BAE, 36); y las del doctor Villalobos, Obras, Madrid, SBE, 1886. Sobre estos personajes vid. el estudio imprescindible de José Moreno Villa, Locos, enanos, negros y niños palaciegos: gente de placer que tuvieron los Austrias en la Corte Española desde 1563 a 1700, México, La Casa de España en México, 1939.

${ }^{4}$ Estudia los diarios del bufón Atanasio Tito Saffioti, ...e il signor duca ne rise di buona maniera: vita privata di un buffone di corte nella Urbino del Cinquecento, Milano, La vita felice, 1997; a partir de citas en epistolarios y otras fuentes, dan mucha información de interés Alessandro Luzio y Rodolfo Renier, "Buffoni, nani e schiavi dei Gonzaga ai tempi d'Isabella d'Este", Nuova Antologia, serie III, vol. XXXIV, 16 de agosto (1891), pp. 618-650 y 1 sept. 112-146; también dedicado a los Gonzaga Giancarlo Malacarne, Le feste del principe: giochi, divertimenti e spettacoli a corte, Mantova, Il Bulino, 2002, pp. 165191, en particular; sobre Francia especialmente A. Gazeau, Historias de bufones, Madrid, Miraguano, 1995.
} 
en octubre del año anterior. Los lugares de procedencia siguen los desplazamientos de Liaño entre Florencia y Madrid, con algunos viajes por Italia, ya que escribe solo cuando se encuentra fuera de la corte granducal (Génova, La Spezia, Roma, Mantua, Barcelona, Valencia, Monzón, Madrid), e incluso una vez desde la misma Florencia pidiendo permiso para desplazarse a pescar fuera de la ciudad. Por otro lado, de las cartas y otras menciones documentales fuera del epistolario, se desprende que Liaño también escribía a Felipe II, pero esa correspondencia, si se conservara, estaría por localizar.

Gonzalo de Liaño, el enano Gonzalillo, Gonzalico o Zalico, no era un hombre común. Tenía una inteligencia aguda, gran conocimiento del mundo cortesano, capacidad organizativa, valor, carácter, don de gentes, gusto artístico y quizá hasta dominio de otras lenguas. Cuando el emperador Rodolfo II estuvo en España entre 1564 y 1571, Gonzalico fue uno de sus criados y luego fue recomendado por Hans Khevenhüller, embajador imperial, a la emperatriz María en una carta:

El personage que la presente dará a V.Mag. es don Gonçalico, gran criado de su Magd. Cathólica y que lo fue tanbién de su Mag. Cesárea [Rodolfo II] al tiempo que estuvo en estos regnos. Suplico a V. Magestad lo conozca por tal y para mandarle tratar por esto y las otras buenas partes que le sobran y faltan como él merece, que todo esto y por la affición que por lo mismo le tengo han sido parte para encomendarlo a V. Magd.... ${ }^{5}$

No era raro que los bufones reales provinieran de las cortes nobiliarias, por lo que podríamos suponer que ese fue el camino seguido por Gonzalo hasta llegar al servicio directo de Felipe II. Sin embargo, sus cualidades le hacían valioso mucho más allá de los reducidos quehaceres del bufón doméstico, y Felipe II supo sacar partido dándole cometidos de agente en el exterior. Así, al menos desde 1579,

\footnotetext{
${ }^{5}$ Apud Cartas de Felipe II a sus hijas, ed. de F. Bouza, Madrid, Akal, 1998, p. 125 en nota y con información personal que le agradezco. La destinataria es la hija de Carlos I y María de Austria, que volvió a España en 1582 después de pasar gran parte de su vida en Bohemia; entonces se recluyó en las Descalzas hasta su muerte en 1603. La llegada de los bufones y locos a la corte real solía hacerse pasando previamente por el servicio de casas nobiliarias, vid. F. Bouza, ob. cit., pp. 41-46; sobre este importante embajador vid. Sara Veronelli, "La historia de Hans Khevenhüller, embajador cesáreo en la corte de España", en J. Martínez Millán, dir., Felipe II (1527-1598). Europa y la monarquía católica, Madrid, Parteluz, 1998, pp. 517-537.
} 
aparece en los registros escritos florentinos como bufón y mensajero real, encargado del transporte de un cuadro para el rey de España. La correspondencia que mantiene Liaño con los Grandes Duques responde, por tanto, a esa función asignada desde la corte española, en un continuo ir y venir de intereses prácticos entre Florencia y Madrid: la obtención de un título para el hijo de Francisco I, el traslado de un escritorio de regalo, el encargo de un cuadro, etc. Si en las cartas se limitara a tratar estos encargos de forma práctica, no pasaría de ser una más de las colecciones epistolares de embajadores, representantes o agentes diversos que tan útiles resultan para el historiador, sin embargo en estas hay mucho más, porque todos los cometidos se disfrazan bajo el espíritu de la bufonería, empleada como medio de abrir puertas y caminos al interés. En este aspecto, quizá la demostración más clara de cómo le sirve a Gonzalo de Liaño su condición de enano y hombre de placer es el epistolario con Bianca Capello.

Bianca Capello era la bella hija de una noble familia veneciana. A los quince años, en 1563, huyó con su amante, se casaron y se instalaron en Florencia, donde llamó la atención de Francisco, entonces aún heredero del ducado. En el verano de 1564 nace su hija Pellegrina y a finales de ese mismo año se convierte en amante de Francisco I, ya duque debido a la abdicación de su padre, Cosimo de Médici. Aunque al año siguiente Francisco se casa con Juana de Austria, Bianca continúa siendo su amante hasta la boda de ambos el 5 de junio de 1578 en el palazzo Pitti, apenas dos meses después de que Franciso enviudara. Gonzalo de Liaño aparece en Florencia un año después de esas bodas, porque en 1579 se le menciona en un documento de 31 de agosto, identificándole como bufón del rey de España y se le encarga el traslado de un cuadro, regalo del Cardenal Fernando de Médici a Diego de Córdoba, jefe de caballerías del rey ${ }^{6}$. Él mismo, en una carta muy formal de 18 de enero de 15807, dirigiéndose al Gran Duque, afirma que llegó de regreso a la corte española a 26 de

\footnotetext{
${ }^{6}$ Apud S. Salort y S. Kubersky-Piredda, art. cit., 2006, p 660, n. 2.

7 Todas las cartas citadas y editadas provienen del Archivio di Stato di Firenze, fondo Mediceo del Principato, en adelante, ASF, MP; aquí 731, f. 20r.-21r.
} 
diciembre de 1579 y le da cuenta de todas las gestiones realizadas en su favor, así como de los encargos recibidos. Respecto a la Gran Duquesa solo dice entonces: "Suplico a V.A. dé un recado a la Gran Duquesa, mi señora, y que estoy aquí para servilla". 8

En 1582 Gonzalo, al servicio de Felipe II, vuelve a Florencia y pasa allí algunos meses entregado a sus gestiones, como era habitual. Sus tratos en la corte incluyeron esta vez de forma bastante cercana a Bianca Capello, con quien advierte que es necesario seguir manteniendo las mejores relaciones. Para ello, apenas ha abandonado la ciudad camino de España, le escribe una carta solo para darle noticia jocosa de sí mismo, apuntar su función de propagador de fama y prestigio y hacerle recordar su presencia palaciega. De momento la carta no trasluce intereses concretos, sino tan solo la voluntad de conservar el vínculo a través del cual en un futuro pueda encauzarlos. ${ }^{9}$

Sereníssima señora, vueso amigo Gonçalico:

Porque sé que mi carta será bien recibida conoçiendo el bien que he reçibido de V.A., y porque no me tengáis por desconoçido, os escribo dando cuenta de mi vita lo primero prinçipal. Salí el día que pati [partí] del pox. (sic) aquea [aquella] noche logo sentí la soedad y començé a entiteçerme, no viendo que me davan en la balca [barca] de mamar, quando V.A. me sodía [solía] regala con aqueios duçe bocaos y particulamente cuando me dava algun recafidio hu orteano ${ }^{10}$. Y aunque V.A. me iama "Salico" y otas nonbes [otros nombres] que me ponía, que todo era queerme bien V.A. Y assí boi pubicando el valor de V.A. y su hermosua, disquiçion [discrección], que mucha gente que ha iado [he hallado] en Génova, cavaieros principales me preguntavan por V.A., que anque [aunque]

\footnotetext{
${ }^{8}$ Dado lo caótico de la ortografía de las cartas, que emplea diversas manos profesionales, regularizo levemente su uso acercándolo al actual, con diversas intervenciones según el grado de pericia del secretario, ya que cuando son italianos escriben un español por aproximación fonética de lectura muy dificultosa.

${ }_{9}$ ASF, M.P., 5931 ff.. 101-102r. El escribiente es italiano y transcribe el castellano con graves errores a partir de la audición del dictado. Algunos de ellos son sistemáticos, por ejemplo, la omisión de la $r$ final de sílaba o de la $l$ intervocálica. Este problema aparece en otras cartas, si bien no de forma tan acusada. Lo más frecuente es el uso de italianismos crudos en el texto.

${ }^{10}$ De otras cartas se deducen los italianismos beccafichio y ortolano. Son pequeños pájaros comestibles, la oropéndola (también papahigo) y el escribano hortelano, que en la correspondencia parecen ser la debilidad gastronómica de Liaño. El diccionario de Autoridades señala del becafigo: "es comida sabrosa en el tiempo que hai higos y se mantienen de ellos" y del hortelano: "Se llama también cierto paxarito semejante al gorrión, que se ceba con leche y harina, y se pone tan gordo y delicado que es comida muy regalada".
} 
tenían fama de V.A., ustavan [gustaban] la buena reaçion [relación] que yo dava, aunque yo tenía maa [mala] lengua y maa de entendé, conoçían que yo tenía le [ley] a V.A. y al gan duque, mi amico. Y esto lo vea V.A., como me vea en España, que su amico Salico tenere la le [ley] como soi obligado a una casa tan prinçipa como es la de V.A.

Yo vine a La Especia y me embagué [embarqué] en una fagata con unos vientos fuetes [fuertes] y assía [hacía] ir las veas [velas] a agua, que pensava que no avía de havé más Salico y dexa la embaxara [embajada]. Y en cuato [cuatro] días que vine de La Speçia, vine d'aquí a Génova con artas paura ${ }^{11}$, poque hazían la vea [vela] a gusto de los maineros, y con esto me consoava [consolaban]: "No habete pauras". Y yo despondía [respondía]: "No tego paura sino de aogame [ahogarme]". Y también acodándome de la pofesia [acordándome de la profecía] que el gan duque me dixo, que me avía de aoga [ahogar] ante que aiegase [allegase] a España. La senoa Leia de negon ${ }^{12}$ basa [besa] la mano a V.A. y al gan duque y al cadenal [cardenal] ${ }^{13} \mathrm{mi}$ amigo que amanecho [me han hecho] mucho favó y regalo por espeto [respeto] de V.A., particulamente el embaxador de su magestad que tan sevido [servidor] es de V. A. y el cadenal Alexandino que está aquí espedando [esperando] al encomendado mayor paa [para] negoçiá los negoçios de su hemano.

Muchas cosas podía escivir [escribir], sino que el secetario y notado [notario] se cansan. Solo os pido que me concebes [conservéis] en vuestra graçia y de la señoa Pelegina ${ }^{14} \mathrm{y}$ del gan duque mi amigo y el cadenal, de meçer [micer] y Jacopino, el de la Mavasía [Malvasía], que quería navegá dento de su hostera ${ }^{15}$ asta España; y el maquesico ${ }^{16}$, que Dios le guade como V.A. lo desea; y mi epeciá amigo Pospeo Colona [Próspero Colonna] ${ }^{17}$ que no puero [puedo] dexa de acordame dónde yo esçebido [he recibido] tanto favo de su casa. Y quando estava enojado, él me quitava la coloa [cólera] y el señó don Joan de Meçes [Juan de Medicis], que aunque me pelava las babas [barbas], no puero [puedo] dexa que V.A. me lo rencomende [recomiende]. Y porque siio [¿he sido?] muy enfaroso [enfadoso] en esta cata [carta], no digo más, sino que N[uestro] S[eñ]or guade

${ }^{11}$ Paura, italianismo, 'miedo'. El viaje que describe Liaño era desde Florencia por tierra hasta La Spezia y de ahí a Génova.

${ }^{12}$ La señora Leia de ..... sin identificar.

${ }^{13}$ El cardenal es Fernando de Medici, el hermano de Francisco I, para quien Gonzalo también hacía de intermediario.

${ }^{14}$ Señora Pellegrina: era la hija mayor de Bianca Capello, fruto de su primer matrimonio.

${ }^{15}$ Hostería. Son varias las veces que Liaño se refiere a micer Jacopino, dueño de la posada u hostería "La Malvasía", en Florencia y a su buena comida allí.

${ }^{16}$ Marquesico, es decir, Antonio de Medici, el joven marqués, hijo de Francisco y Bianca, nacido antes del matrimonio de sus padres y futuro heredero. A la muerte de Francisco I y Bianca, el cardenal Fernando, sucesor del ducado, descubrió sospechosamente una trama que desvelaba que Antonio no era hijo de Francisco y Bianca, sino el fruto del parto de una campesina, que ella había hecho pasar por hijo propio a fin de ofrecer al duque el ansiado heredero, atándolo definitivamente a ella. Vid. C. Giachetti, ob. cit., y Guglielmo Enrico, "Della morte di Franceso I de'Medici e di Bianca Cappello: relazione storica", Archivio storico italiano, XVIII (1863), pp. 19-81. Liaño alude en muchas cartas al deseo de Bianca de tener un hijo y en ocasiones a noticias sobre sus embarazos, que siempre resultaron ser falsos.

${ }^{17}$ El anciano cardenal Granvela era entonces secretario de estado en sustitución de Antonio Pérez. 
[guarde] la sereníssima persona de V.A. como su amico Salico lo desse [desea]. De Génova a 12 de noviembre 1582.

Bueso amico vedadero que buesos pies y manos bessa muy cieto.

Gonçalo de Liaño

Pasado un tiempo breve, el 15 de enero de 1583, escribe para asegurarle que está llevando a cabo sus encargos y sobre todo para recordar cómo ha sido de placentera su estancia en Florencia. A través de la descripción de esas bromas, atisbamos al bufón en el ejercicio de sus funciones cortesanas

Sereníssima y verdadera amiga:

Porque vuestro amigo Gonçalico ha llegado a esta corte a ocho del mes de henero, a mediodía allegué a esta corte y me apeé en casa del señor Bartolomé de Santoyo, ${ }^{18}$ y començé ha hazer la embaxada que me encomendastes. Sabe Dios cómo yo quisiera yr dentro desta carta, con que yo os pudiera hazer reýr con los muchos quentos que en esta jornada me ha acontecido. Aunque mi señora doña Ana se holgó tanto con el presente y con la carta que la escribistes y está tan desseosa y alborotada de abelladado ${ }^{19}$ una amiga tan grande como bos; y me remito a que ella os escriva y os [dé] relaçión del desseo que tiene d'escrivir. Yo boy tomando lengua ${ }^{20}$ desta corte; no estoy olvidado de lo que me avéys encomendado ni soy yngrato, porque savé que tengo ley y os la tendré y ser coronista de vuestro balor y hermosura; y la verdá (sic) que os diga ya me muero por veros. Acordaos de Gonçalico, que aunque estoy en ausençia, no tengo quien me regale tanto como vos me avéys regalado, que en esta corte estoy publicando las muchas merced y regalo que me avéys hecho. Acuérdome de Xacopino de la Balmasía y de todas las osterías y de los vinos rojos; y también de la burla que el Gran Duque me hizo, quando estuve ocho días que no pude comer más; también sospiro por los recafidio ${ }^{21}$ y ortelanos, y aquellos bocadicos que en vuestras mesas me daban. Aquí en esta tierra me ban perdiendo el respeto, ya me llaman de vos y hallé mucha fantasía, y me muero ya de hambre. Y la ora que escrivo esto me boy acordando de que no tenía quien tanto me regalava y tanta lástima me tuvistes el día quando me dio el Gran Duque aquella medeçina, que en una copa de salsa que el señor Gerónimo, el copero del Gran Duque, me dio a beber ${ }^{22}$.

${ }^{18}$ Bartolomé de Santoyo estaba a cargo del guardarropa real y su hermano Sebastián era secretario de Felipe II; "mi señora doña Ana", a quien luego menciona, era Ana Liondegardo de Zárate, esposa de Bartolomé.

${ }^{19}$ Abelladado: Posible errata por "haber hallado", con aglutinación de vocales.

${ }^{20}$ Lengua: en el sentido de 'informe' o 'noticia', que recoge Autoridades.

${ }^{21}$ Transcripción españolizada o más bien fonetizada del término "beccafico", curruca mosquitera, becafigo o papahigo, es decir, un pajarillo que se comía.

22 Por otras cartas sabemos que lo que le dieron fue un laxante. 
Perdóneme, señora, porque no la escrivo más largo, porque me quiero ir a ber al cura de Carbanchel ${ }^{23}$, porque en esta corte no me dexan y estas campanas quando tañen a muerto me congojan. A mi espeçial amiga mi señora Pelegrina, y al señor Marquesico, y a las Prinçesas y al hijo del señor Pablo Jordán; que Dios me libre de la negra, que no estoy olvidado de la fuerça que tiene; y a Madalena y a Elena, la vieja la que os viste, y a todas las damas y al señor Ribera, que es el que ha de ser coronista desta carta; y el caballero Espina su paje. Y buenas noches os dé Dios y a mí me libre Dios del espíritu que me hizo cagar de miedo la noche que dormí en palaçio. Y por no ser enportuno aunque sé yo que mis cartas no os enfadan. El sábado de Madrid a xv de henero de 158iij.

Vuestro verdadero amigo para lo que me mandáredes,

Gonçalo de Liaño ${ }^{24}$

Para Liaño 1583 fue año de estancia en Madrid, al menos hasta septiembre, cuando ya está preparando el viaje de vuelta a Florencia con los últimos encargos. En ese período escribe once cartas a la Gran Duquesa y cinco, al menos, al Gran Duque. Aunque casi nunca falta la mención de las gestiones encomendadas, estos temas tienen atención preferente en las cartas dirigidas al Gran Duque, por lo general más extensas. En las destinadas a Bianca Capello, se incide sobre todo en su función de pregonero del prestigio de la duquesa: su belleza, bondad, generosidad, grandeza de la corte, etc. Subraya sus relaciones en la corte española para dejar claro que esta divulgación se hace en los foros aristocráticos, los del poder en definitiva, lo que le sirve a Liaño a la par para encarecer su propia importancia y función para la Gran Duquesa, un valor que puede ser traducido en términos económicos a través de peticiones de dinero como debida recompensa. Nuevamente el envoltorio de estos elementos fundamentales son los recuerdos y exaltación de la vida en Florencia, además de esa devoción cortesana que le rinde.

Sereníssima señora.

Dios os guarde mill años por el fabor que me hacéys en escrebirme y en acordaros de vueso amigo Gonçalo, que tanto os desea servir. Y el rey a gustado de la quenta que [he] dado tan buena a cosas que tocan a vuestra hermosura, que me ha preguntado tanto particulares cosas. Yo he dicho de vuestro valor y discreçión y lo que os queréys y que no

\footnotetext{
${ }^{23}$ Se trata de un personaje que menciona en varias de sus cartas y que posiblemente fuera conocido de Liaño, ya que no lo encuentro documentado como personaje folclórico.

24 ASF, MP, 5931 f. 455.
} 
abía hallado muger que tan gran pecho como tenéys, que bastáys gobernar todo un mundo, y en entretener tantos príncipes que han pasado por Florençia, y los regalos y caricias que les abéys hecho, particularmente al Arciduque y a la condesa de Olibares. Y cómo os llamaba "serenita" y las caricias que hacéys a las princesas. También le dixe la muerte del príncipe y el regalo que tube y icistes todo lo ynposible; y que estubistes mala del sentimiento que ycistes, que vuestra alteza y el granduque los daba de comer de su mano; y que fuystes la Anunçiada de Florencia bendita y cómo a suplicar que le diese salud. También le dixe cómo coméis juntos y cenáis yuntos y que quando el Gran Duque ba, acabáys con él siempre. Preguntóme que en las villas en qué pasabays el tiempo. Yo dige que jugabays algunas veces con el Gran Duque al xiquete, y otras muchas cosas que por no ynportunar no las digo. Solo os digo que yo soy tronpeta en esta corte, que doy boces publicando lo que merecéys y lo que hazéys a todos los cortesanos desta corte y señoras, que son las mayores bachilleras de preguntarme por vuestra alteza. Y algunas señoras me quieren dar algunas cosas quando yo parto desta corte.

El negocio del Marquesico ablé a su Magestad y le besé las manos de parte de vuestra alteza, que se me abía olbidado, y me dixo que lo mandaría despachar qu'él no tenía culpa, sino el cardenal de Aranbela ${ }^{25}$, que lo despacha; creo que lo despachará.

Quéntame vuestra alteza la buena vida que buesa alteza se ha dado con el Gran Duque mi señor en el estado de cena, del buen cabrito y faysanes y del buen bino y otros bocaditos regalados que se han comido, que al seguro que quando me leýan la carta, sospiraba y dábame v.m. apetito. Que si tubiera alas para bolar, bolara como alcón por beros y por comer de aquellos regalos que me dize en la carta de vuestra alteza. Plega Dios que Dios os quarde mill años como bos deseáys y bueso amigo Gonçalito, que os lo desea, y os dé un ijo de bendición, que es lo que deseamos todos los que somos vuestros criados. Y porqu'es tarde y me llaman para cenar mi amigo el embaxador, no escribo más, sino que me concedáis vuestra gracia y las princesas y de las señoras Peregrinas. Y de mi amigo el señor Ribera me recomiendo, que sabe Dios cómo yo querría yr dentro esta carta, y me pesa de no poder acerlo haora y pagar la buena boluntad que me tenéys. De Madrid xv de abril de 1583 años, su berdadero amigo para lo que me mandays. Gonçalo de Liaño. ${ }^{26}$

Tiene particular tono jocoso una carta un poco posterior, donde declara su amor a la Gran Duquesa. Se trata de una fórmula frecuente entre los bufones de ese tiempo para provocar la risa, porque es la que utiliza Magdalena Ruiz con el Duque de Alba cuando le dice que desea darle cuatro besos. Asimismo es habitual encarecer

\footnotetext{
${ }^{25}$ Aranbela: Granvela.

${ }^{26}$ ASF, MP, F. 5934, f. 7.
} 
al amo subrayando la soledad que se siente por su ausencia y que solo por imposibilidad no se va a verle ${ }^{27}$.

\begin{abstract}
Serenísima señora
Estoy muy gozoso con dos cartas que tengo vuestras y tráigolas comigo, y publicando en esta corte el fabor y la merced que me hazéis, y en lo que toca a publicar vuestro balor y hermosura y discreción. Aunque su Magestad es preguntador y quiere saber muchas particularidades, y se huelga de saber la ley ${ }^{28}$ que tengo con V. A., particularmente con estas señoras de la corte, que cada día nunca me dexan, porque son curiosas de saber vuestro trato y valor. Y la Marquesa del Valle, que es muy amiga y os desea mucho servir por averle yo contado de vuestra virtud bondad y hermosura y discreción, os quiere tanto syn averos visto. Y así estando anoche con ella hasta las doze de la noche, me dio un pañiçuelo de cadeneta para mý y también unos guantes, y pienso que me los dará. Yrán con este hordinario ${ }^{29}$ para que veáys las curiosidades de esta corte. Este presente es de Gonzalico, vuestro amado, que syempre va publicando vuestro valor. Y barrunto que estoy enamorado de vos, y esto lo digo entre mí y vos y no lo sepa el Gran Duque, porque los amores sy no son secretos, no son estimados. Y particularmente de los guisadicos y regalos que me dábades, bien tengo entendido que me llamáis a la comida quando coméis y cenáis y lo mismo hago yo. Dios me dexe veros muy presto, que ya esta corte me cansa sy la Marquesa del Valle no me remediase, que la verdad que diga también estoy enamorado de ella, porque ella lo mereçe y muger espiritual y discreta no la ay en esta corte syno ella. Y si queréis preguntar quién es, ynformaos del Gran Duque, que ella conoce muy bien. $\mathrm{Y}$ porque haze calor y ay falta de agua en esta tierra, no os quiero enfadar sino que me conservéis en vuestra gracia y del Gran Duque y del Marquesico, que harto he hecho con el Rey para que acabe su negocio, y creo que se acabará, porque el Rey tiene muy gran voluntad de daros gusto. Y daréis mis besamanos a la señora Peregrina y que si ella es pelegrina, yo soy esclavo y peregrino hasta que la vea; y de las Princesas, mis señoras, que las guarde Dios mill años; y el señor Jacopino, que hartas vezes sospiro por él; y Ribera y Sigismundo, que les beso las manos. De Madrid a xxiiij de abril 1583.
\end{abstract}

A su serenísima señora, para lo que mandáredes Gonzalico, vuestro amigo verdadero,

Gonçalo de Liaño ${ }^{30}$

${ }^{27}$ Cf. F. Bouza, "La estafeta...", art. cit., pp. 112-114, cartas de Magdalena Ruiz y Agustín Profit al duque de Alba; también es un rasgo risible de algunos enanos en los libros de caballerías, vid. J. M. Lucía Megías y E. J. Sales Dasí, "La otra realidad social en los libros de caballerías castellanos. 1 Los enanos", Rivista di Filologia e Letterature Ispaniche, V (2002), 9-23. Se advierte diferencia entre el estilo y el de Francesillo de Zúñiga, mucho más hiriente y comprometido; o las de Manuel Gómez, muy posteriores, que edita F. Bouza, art. cit.

${ }^{28}$ Ley: 'lealtad', 'fidelidad'.

${ }^{29}$ Hordinario, por 'correo ordinario' con el que pensaba Liaño mandar su carta.

${ }^{30} \mathrm{ASF}, \mathrm{MP}, 5933$ f. 171r.-v. 
Cuando ya está próxima la partida, el tono de las cartas se vuelve más urgente, subrayando la necesidad de verla, la añoranza de Florencia, los aspectos que la hacen superior a Madrid y dando pinceladas sobre su vida privada a través de la mención de su esposa, con la que se ha casado ese verano. La marquesa del Valle, doña Magdalena de Guzmán, es uno de los personajes de la corte con quien más relación parece tener Liaño, la visita en todas sus estancias en Madrid y la menciona con frecuencia elogiosamente en sus cartas con los grandes duques ${ }^{31}$.

Sereníssima Gran Duquesa mi señora:

Gonzalico, vuestro amado, estando ${ }^{32}$ el contendo que recibió con vuestra carta que no lo sabrá decir ni encarezer en ésta, que yo os prometo que cada ora se me haze un año asta veros, que no hai cosa que más desee. Y no me detengo por otra cosa, si no es por esperar pasaje de galeras, porque bos y el gran duque me teneis enechizado, que aunque estoi casado, dejo mi muger en un monesterio por hiros a ber. Y por estar yo más seguro de los peligros desta corte y más teniendo la mujer hermosa, y ansí se á de mirar mucho por la honrra, aunque ella tiene mucha, que si no fuera ansí, no me juntara con ella. Yo me quisiera allar allá en esta primabera más que no a la merced que su merced me a echo, para gozar de los melones y otros frutos tan regalados como haí se allan y ver desos contadinos $^{33}$ con tan lindas frutas como llevan a esa plaza, con todo lo demás que es muy bueno y mejor que lo de acá, y confiado que me beré presto allá, donde me pienso de vengar. No diremos que la marquesa del Valle es tan principal y cumplida en cosas sus cosas que os quería enbiar un presente con este hordinario y como por la posta no se puede enbiar mucho, pero y ansí se abrá de quedar asta que yo baya, que será presto placiendo a Dios; el qual hos me guarde mill años. A las princesas y a la señora Peleghrina mi besa las manos; y al marquesico, y al señor Pandolfo, y Zigimundos y al señor Ribera mis encomiendas y contando nuestro señor. E de Madrid primero de agosto de 1583

Vuestro berdadero amigo para lo que mandaredes Zalico, que bien os acordaréis,

Gonçalo de Liaño ${ }^{34}$

\footnotetext{
31 Sobre la personalidad de la marquesa, su capacidad gestora, su prestigio y su afición coleccionista vid. L. Fernández Martín, "La marquesa del Valle: una vida dramática en la corte de los Austrias", Hispania, 39 (1979), pp. 559-639.

32 Gonzalo nunca escribe sus cartas, sino que las dicta a un secretario profesional, poniendo solo la firma de su mano. De ahí los problemas con la ortografía que antes veíamos y con otros errores posiblemente de audición, como el estando que seguramente debiera ser es tanto.

${ }_{33}$ Contadinos, italianismo, 'campesinos'.

34 F. 5934 c. 119, De Gonzalo de Liaño, Madrid, 1 de agosto de 1583
} 
Florencia no era el único destino de Gonzalo en Italia. En los viajes de ida y vuelta o por encargos particulares, debía pasar por otras ciudades. Después de haber estado un tiempo en Florencia, debe ir a Roma, donde la vida no era menos animada o quizá lo fuera incluso más. En Roma Gonzalo describe su relación con un círculo de españoles e italianos, posiblemente formado por gente de placer como él y cortesanas, con el que entretiene sus ocios. El contenido de la siguiente carta está destinado sobre todo a divertir a la Gran Duquesa con las anécdotas de su viaje de Florencia a Roma.

Sereníssima señora,

Carta de Gonçalico scrita en Roma

La hora que os scrivo esta carta, acabo de jugar con Sangaleto y Tuya, que es aquel bufón que vino con el cardenal de Medicis, y me han ganado a la primera ${ }^{35}$ entre los dos ocho scudos, en la huerta de la Trinidad, que si no fuera porque son amigos de bandidos, creo que me diera de moxicones con ellos. La primera jornada que hizimos quando salimos de Florencia allegué muy cansado, y dormimos en una casería de un hospital de Sena y nos dieron muy bien de cenar y muy buenos vinos, aquel prete que es mayordomo del Gran Duque. Y yo no pude comer de puro cansado, y las nalgas estavan tan sacudidas del cavallo, porque se me cansó un cavallo y me hizo andar dos millas a pie hasta llegar a la posta. En fin del buen cardenal de Medicis me remedió con una mula regalada, que si no fuera por él, yo fuera muerto, y dormí aquella noche con espuelas y hize cuerpo de guardia. Todo lo que me sucedio fue aquel día.

Otro día tuve buena cama, aunque llegué muerto y el viernes passamos por el lago de Bolsena, que el cardenal me dixo que fuesse con él en una barca. Yo y Sangallo veníamos en una carroça, que como portones ${ }^{36}$ y covardes no quisimos yr con él, y después no quesiéramos que el cardenal se huviera embarcado, que como vimos el lago tan alterado, el Sangaleto hizo tantas lamentaciones y llamando a Dios y a la Madona de Lorito ${ }^{37}$, que yo y él lloramos. Y en fin se apeó del coche y mandó la marcha a dos postillones ${ }^{38}$ para que bolviessen atrás y le traxessen la nueva, pero al fin el Cardenal se rio y no dio a entender lo que havía padescido, antes mostró el rostro muy alegre. Aunque me dixo un cavallero romano: "Gonçalo, si tu vinieras con nosotros, yo te aseguro que te murieras de temor". Y digo que él tiene grandíssima razón, porque como soy tan gallina, yo me

\footnotetext{
35 Primera: juego de cartas, que describe el Diccionario de autoridades.

36 Portones: no existe ninguna acepción del término en castellano o de un posible italiano que tenga valor adjetivo. Me sugiere con buen tino Elena di Pinto que sea una deformación de poltrone ,'gandul, holgazán', con la metátesis $l / r$ característica del Lacio.

${ }^{37}$ Lorito, la Virgen de Loreto, una de las advocaciones italianas más famosa.

38 Postillón: mozo que va a caballo delante de los que corren la posta para guiarlos y enseñarles el camino (Autoridades).
} 
muriera y aun cagado en las calças. Esotro día fue el sábado, entró el cardenal a mediodía y yo me quedé atrás, y la amiga de Tuya salió en un coche a una porta a recivirle, y hiziéronse tantas caricias y se besaron y lloraron de contento, y vinieron a Roma y entrambos a dos se fueron a una stufa ${ }^{39}$.

Esto es las nuevas que hay, aunque en casa de Jacobo Boncompagno estava un bandido que Jacomo lo havía asegurado, mas su Santidad lo ha mandado prender y sacarlo de su casa. Yo tengo desseo de acabar mis negocios y después negociar lo que $\mathrm{V}$. alteza me havéys encomendado, que yo tengo más desseo de andar allá, porque aquí me muero de calor. Ni he començado a visitar a nadie, porque no era venido mi baúl, de mañana començaré y porque tengo el humor. Nuestro Señor os guarde a vos y al Gran Duque como vuestro verdadero amigo Gonçalo, que tanto os ama, dessea. De Roma y de mayo a 15 de 1584

Vuestro verdadero amigo para lo que me mandareys,

Gonçalo de Liaño ${ }^{40}$

La vida en Roma, tal como la cuenta Liaño, parece ofrecer constantes diversiones, a las que no hace remilgos, según le relata a la Gran Duquesa con el fin de divertirla. Los halagos sobre la fama que tiene, la que él le proporciona y su enamoramiento, expresado en conceptos neplatónicos propios de la poesía culta, desembocan en una petición de recomendaciones para Giacomo Boncompagno, hijo del papa Gregorio XIII"1, y para el Cardenal d'Este, es decir, Luigi d'Este ${ }^{42}$, sin explicarle realmente para qué las necesita, puesto que la mención de las cartas de las damas le da una excusa de apariencia galante, pero muy poco verosímil. Gonzalo recurre casi siempre a estas cartas de presentación para asegurarse una buen recibimiento, además le ofrecen una forma de enaltecer su prestigio por medio del elogio ajeno y dan garantía a sus palabras, todo ello para asegurarse el buen éxito de sus gestiones.

Serenísima Gran Duquesa y especial y verdadera amiga:

Para mí es tanto el contento quando veo carta vuestra que me [roto ¿vuelvo?] más loco de lo que estoy, de contento de ver que estoy tan en vuestra buena gracia y del Gran Duque.

\footnotetext{
${ }^{39}$ Stufa: Entonces en Roma se conocían con el nombre de stufe los baños públicos.

40 ASF, MP, 5936, ff. 544 r.-v.

${ }^{41}$ Giacomo Boncompagni (1548- 1612), duque de Sora y marqués de Vignola, desempeñó numerosos cargos militares y administrativos en el Vaticano.

42 Luigi Cardinal d'Este (1538- 1586) era uno de los cardenales más poderosos del Colegio y mantenía una excelente relación con Francia, país del que fue nombrado Cardenal Protector.
} 
Y no sé si yo estoy enamorado de vos, y esto es para entre mí y vos, y no lo digáys al Gran Duque porque no me pida celos, porque si como o çeno, que es quando mi coraçón está contento, entonces me acuerdo de mi buena Gran Duquesa y no tengo otro desseo sino bolverme a estar con vos. Y no podrá ser menos, porque teniendos vos el alma, el cuerpo ¿cómo podrá estar sin el alma? Y verdaderamente en este particular os podría dezir muchas cosas, porque vos lo merecéys y hartas veces me acuerdo, que quando estava yo afligido y desconsolado, érades vos mi consoladora. Anoche cené con la señora Clelia y estuvimos muy alegres, porque tuve el humor y tomé un laúd, y dixe tantos disparates que la señora Clelia se caýa de la silla riendo. Y también merendé en casa de la señora Costanza y estuvimos muy alegres, y vino el cardenal Sforza, que en viéndome comer, le dio apetito. Y está tan flaco que os espantaréys, que si no tubiese sperança de su mocedad, yo entiendo que tarde convalescería. Yo vi la processión el día del Corpus Christi, que fue cosa de ver, y estuve a la puerta con el cardenal que le cabe governar la processión con otros dos obispos, y hizo muy bien su officio. Y nunca me quité de su lado, porque no me diessen alguna bastonada tudesca estos de la guarda y el señor Jacomo Bonconpagno me dio la mano drecha por ser hombre que lo merecía. El domingo soy combidado con Tuya con su amorosa en una viña, Sangaleto haze la costa. La embaxadora y el embaxador me hazen muchos regalos, aunque el coraçón del embaxador no es muy cattólico, porque alguna vez [roto ¿me?] quiere dar xaque de peón y yo le respondo con el cavallo sobre [roto ¿a-?] quel amigo que está en Nápoles. El Gran Duque lo entenderá muy [roto ¿bi-?] en.

Yo voy entendiendo en procurar de despachar y hazer lo que vos [roto ¿me?] mandáys, yo me remito al Cardenal, que él dirá quando andare [roto ¿allá?]. Asta aora no he podido alcançar dineros, no hazen sino combidarme a comer y banquetearme, que es lo que yo no he menester, y danme con la señoría ilustrísima tantas que soy hombre que la vendería por qualquier dinero que me diessen. Y es tanto lo que podéys en esta corte y vuestro valor y fama que buela acá. Los españoles que no traen otro en la boca sino alabanças vuestras y en las occasiones que me hallo me da Dios tanta gracia en esto que sé muy bien dezir mi razón en cosas que tocan a vuestro servicio, de muchas mercedes que hazéys a vuestro amigo Goncalico. Quiero que hagáys esta, que scribáys a Jacomo Boncompagno y al cardenal de Este en recomendación mía, porque tengo tantas memorias de señoras de la corte que me cansan y soy tan amigo de hazer lo que se me encarga que no querría por ninguna vía faltar. Y porque soy cierto que no me havéys de desamparar, sino siempre favorecer a Dios. Gran Duquesa y Gran Duque y plegue a Dios que presto me vea con vosotros, que no desseo otra cosa sino daros contento y gusto, y procurad de conservar a Gonçalico en vuestra buena gracia. De Roma y de junio el primero de $1584 .{ }^{43}$

Vuestro verdadero amigo que tanto os dessea servir,

Gonçalo de Liaño

${ }^{43}$ ASF, MP, 5936, ff. 812r.-v. 
Felipe II pasó mucho tiempo de viaje en 1585. Primero fue hasta Zaragoza, donde el día 14 de abril casaba a su hija, la infanta Catalina Micaela, con el Duque de Saboya. Después celebrará cortes en Monzón y, por último, irá a Valencia con el mismo propósito, donde todavía está a comienzos de 1586. El rastro que deja el epistolario de Liaño sigue de cerca estos traslados de la corte después de llegar desde Italia en enero, llevando regalos y para acompañar al Duque de Saboya desde Barcelona a Zaragoza. En febrero, mientras está en Vilafranca del Penedès, le ocurre una de esas desgracias propias de su condición de agente: el pardo o tigre que traía a España por encargo del Gran Duque, se muere. Las explicaciones que da por carta procuran exonerar al cuidador del animal:

no se á podido haçer más, de lo que yo doy mi palabra a V. A. serenísima, de que el pardero es tan hombre de vien y tan afiçionado al serviçio de $V$. alteza que no puede ser más. Y ansí le aconsejé que, pues el pardo hera muerto, sería mejor volver a Florençia; ansí lo a hecho. Áme pessado tanto a mí como si se me ubiera muerto un hermano mío ${ }^{44}$

No fueron buenos tiempos para el pobre Gonzalo, que tiene que sufrir maltrato para diversión del Duque de Saboya, según relata Arandilla o Arandica, otro agente, bufón y amigo ${ }^{45}$, que fue parte doliente de la misma burla cortesana, en la que destaca los arrestos de Gonzalo atacando:

En lo que toca a Gonzalillo y a mí, abías de saber que [el Duque] trae un loco o por mejor dezir un boracho [sic] que á enbestido con Gonzalillo un día delante el duque. Y aquel

\footnotetext{
${ }^{44}$ ASF, MP, 771, ff. 439 r., carta al Gran Duque desde Villafranca, 7 de febrero 1585.

45 Según S. Salort y S. Kubersky-Piredda, art. cit., 2006, p 660, n. 5, Arandilla era también un enano agente entre Austria y Toscana, cuyo nombre auténtico era Nicolás Castellanos. Efectivamente las numerosas cartas que se conservan de Arandilla al Gran Duque mencionan sus estancias en la corte del emperador, en Saboya, en Florencia y también en España; en ellas se refiere a Gonzalo con admiración y encarecimiento en bastantes ocasiones. Entre ambos hombres debía existir una relación fraterna, porque en carta de 3 de febrero de 1586 (ASF, MP, 5938, f. 629-630) Gonzalo dice a la Gran Duquesa: "a Arandica yo le he favoresçido tanto con el rey que le he hecho despavilador y adreça la lumbre y está muy cuerdo y no juega, y muy agradesçido del bien que V.A. le ha hecho; y agora está de manera que me puede a mí favoresçer". Ese era el cargo que ocupaba anteriormente el propio Gonzalo, a juzgar por la carta del embajador de Saboya en Madrid al Duque su patrón en 1583 para presentarle: "Callaré que es despavilador del rey y su mucha privança por dezir en dos palabras a Vuestra Alteza, que es la crónica de toda la corte", apud S. Salort y S. Kubersky-Piredda, art. cit., 2006, p 660, n. 1. En carta de 4 de julio de 1583 le dice al Gran Duque: "dixéronmi que my responderiano quando yo me partiesse para V. A., al qual tiempo yría allá como medio embaxador" (ASF, MP, 762, ff. 210-211); y en la de agosto de 1587 le explica a la Gran Duquesa, con cierto tono jocoso, que va como embajador y cuáles han de ser los recibimientos.
} 
mesmo día azerté a yr yo a la comida y llego tarde, y como llego, bi a mi amigo Gonzalillo y me contó lo que abía pasado, de manera que como bi lo que abía pasado con Gonzalillo, más quisiera ser en vuestra mesa que allí, porque también ubo la parte mía para mí. De manera que Gonzalillo fue más baliente, porque el barón ni todos aquellos caballeros no fueron bastantes para quitarle que no arremetiese a él, y le sacudió tan bien que fue el otro más malparado de mí. Luego se yzieron las pazes por orden de aquellos caballeros que allí estaban y como no soi muy baliente, luego se confirmaron las pazes. D'allí a tres días bolbí a la comida del Duque y el señor loco tomó un laúd qu'es del Conde de San Román, qu'está aquí arto biejo, me sacudió con él de manera que ya soi músico de laúd. Otro día siguiente, qu'es el mesmo día, por un no sé qué que dije al Prínzipe de Oria, que fue que estando jugando Gonzalillo con él a piquete, le dije que para entretenerse era bueno Gonzalillo, que no yo quería jugar con él, porqu'era para destruylle" 46

Durante esos viajes sigue escribiendo a la Gran Duquesa. Su confianza epistolar se estrecha y las cartas reflejan una de las fórmulas jocosas que debían ser comunes entre la bufonería y sus señores: la del vínculo amoroso entre ambos. Gonzalo, desde su condición de enano y precisamente por el contraste físico con la dama, que a los ojos de todos convierte el amor en imposible y produce hilaridad, se refiere en ocasiones a la duquesa como su amor "a lo divino". Con él abre la siguiente carta, que luego trata sobre la eficacia de sus gestiones, dando detalles concretos de lo hecho y remitiendo a terceros que pueden dar fe de ello. Efectivamente el único medio que tenía Gonzalo para demostrar su posición en la corte y su proximidad al rey era la confirmación que podían aportar otras personas del mismo entorno, de ahí que sea frecuente la mención de gente de confianza de los Grandes Duques como testigos de su actuación. Esta exposición de su amor y trabajo le lleva en la última parte de la carta a poder reclamar pago en efectivo y a quejarse de la tacañería del Gran Duque, que menciona sin rebozo alguno.

\footnotetext{
46 Ibidem ff. 421r-422v; carta de Arandilla al Gran Duque desde Villafranca, 12 de febrero 1585.
} 
A la Serma. señora la Gran Duquesa de Toscana, mi sra. ${ }^{47}$

Por hacer pesar al gran duque os quiero escrivir desta manera, amor mío a lo divino. Una carta me dio Luis de Ovada ${ }^{48}$, que aunque estava yo triste y muy penoso de la enfermedad de mi muger, me dio tanto contento que se me alegró el coraçón y con las dulçes palabras que en ella me escrivís me tocó al coraçón, de manera que me quitó el dolor que yo tenía. Sepa V.A. que me debe mucho, porque he dado tan buena relaçión al Rey de V. alteza que si mucho os quería antes, mucho más os quiere aora. Y la embaxada está muy bien hecha, de manera que la Marquesa del Valle no se quexará y remítome al Sr. Luis de Ovara, que dirá a V. alteza quién es Gonzalico, y lo que yo merezco, y la reputación y fama que he ganado más que nunca, que anoche me dio un laxarico ${ }^{49}$, un poquito de pan pringado y me dixo que le dixesse cómo me sabía. Y dixe que me sabía bien y mandóme traer a beber, que estos regalos no se hazen a todos ${ }^{50}$. De las ferias ${ }^{51}$ sobre la mesa y el escritorio yo haré de manera que el Gran Duque quede espantado, y esta le dirá V. A., que yo no lo escrivo al Duque.

Dize Luis de Ovara que mereçía yo mucho, porque sabe él lo que yo he dicho al Rey del Gran Duque, y que el Rey está muy satisfecho de V. altezas por la relaçión que yo le he dado, y que aunque el Gran Duque me diera dos mil escudos, muy poco para los servicios que yo le he hecho por acá en esta jornada. Y todos me an preguntado, hasta el mismo Duque de Saboya, y yo les he dicho a todos que me avía dado mill escudos, y sabe $\mathrm{V}$. alteza que no me dio sino çien escudos para traher tantas cosas como yo truxe a mi cargo. Y el día que me los dio, los pagué a Baltasar Xuárez ${ }^{52}$, que se los devía, y tomé doçientos escudos a cambio, que se los pagué al dicho Balthasar; y para que V.A. lo crea, en los libros de Balthasar Suárez se hallarán. Mas por esto no he dexado yo de hazer lo que debo, mas perdóneme V.A., que es un poco apretado ${ }^{53}$ y esto no le he querido escrivir hasta aora que lo digo, que ya el Gran Duque y V. A. tendrán cartas de su Magestad en agradeçimiento del presente. Pluguiera a Dios que el Gran Duque fuera como V.A. y tan liberal, que al fin V.A. me regala y me da cien escudos cada año y me

47 ASF, MP, 5940 h. 6r-v. La carta está falta de una hoja y, por tanto sin firma ni data; no obstante se puede suponer que le corresponde el f. 25 del mismo legajo, que no pertenece a otros documentos y donde consta la firma y se fecha en Monzón a 24 de agosto de 1585, que asignamos a esta.

${ }^{48}$ Luis de Ovara es el cremonés Luigi Dovara, agente mediceo en la España de Felipe II, de ahí que Liaño remita a su testimonio para asegurar la veracidad de sus palabras. Vid. Guido S. Picenardi, "Luigi Dovara, gentiluomo cremonese: agente mediceo alla corte di Filipo II", Archivio Storico Italiano, XLVII (1911), pp. 49-128.

${ }^{49}$ Laxarico: término no aclarado.

50 No queda claro en el texto si esta deferencia es de la Marquesa del Valle o del Rey. En otras ocasiones se menciona en la correspondencia la presencia de Gonzalo durante las comidas de sus amos y su participación en las mismas por medio de los bocados delicados que le ofrecen, por los que él siempre afirma suspirar.

${ }^{51}$ Ferias: regalos. Se debía tratar de un escritorio y una mesa de gran valor que el Duque regala a Felipe II y por el que espera un reconocimiento sustancial.

52 Baltasar Suárez era agente financiero en Florencia, desde donde mantenía correspondencia y relaciones con España.

53 Apretado: 'tacaño'. 
socorríais con dineros. En fin vos sois mi esperança y mi consuelo. ¡Viva, viva la Gran Duquesa y también el Gran Duque, es buen amigo y compañero y da poco dinero!; y Xixumundus ${ }^{54}$ y Ribera, que son buenos compañeros y amigos de V.A.; y a mi señora Peligrina, que es aquella que salió del paraýso terrenal cantando el alleluya. Sabe Dios cómo yo quisiera yr dentro desta carta a ver aquel rostro angelical y besar aquellas vuestra manos, que quitan quanta melanconía ay. Y porque me avéis de responder a esta carta, no digo más esperança.

Vuestro Gonçalo de Liaño.

La siguiente carta se estructura exactamente a la inversa. Primero Gonzalo le da cuenta de sus buenos oficios y le plantea un tema que aparece en la correspondencia de esa época con ella y con su esposo: la necesidad de ampliar las indulgencias concedidas a los rezos en uno de los cuadros que habían enviado desde Florencia. Sin duda se trata de un asunto de interés para Felipe II, que quiere colocar el cuadro en El Escorial, pero al que no le basta una bula privada, sino que desea hacerla extensiva a todo el que rece ante el cuadro. Para ello era necesario obtener un documento papal, que es el que se solicita por medio de los Grandes Duques. En la segunda parte de la carta, Gonzalo despliega todo su encanto de bufón para retratarse a sí mismo con su esposa parodiando los gestos cortesanos. Luego narra una breve anécdota escatológica con su hijo, del que concluye: "asta en esto ubo de pareçer a mí". La risa que estas situaciones provocarían en la Gran Duquesa se aprovecha para pedir que le envíen unas cajas con comida toscana y apuntar que hay una deuda pendiente por lo que trabaja para ellos. El interés nunca anda lejos.

Állome con una carta de vuestra alteza de diez y ocho de agosto bien ençecinada ${ }^{55} \mathrm{y}$ entendido el amor que vuestra alteça me tiene, que bien me lo deve por la affición que la tengo y la buena amistad que é echo y relación que é dado a la Marquesa del Balle de vuestra alteça, que ya me entiende. Y remítome a Luis de Obada, que ya á partido de Monçón para allá, que V. alteça se podrá informar dél lo que á echo el buen Gonçalo; y como su Magestad esté en esta corte, se conoçerá. Para el quadro que envió vuestra alteça a su Magestad gran cosa fuera que se embiara un jubileo, para que todos los que reçasen en el retrato se pudieran ganar las graçias que se conçedieron a vuestra alteça por el papa

\footnotetext{
${ }^{54}$ Xixumundus: Segismundo, al que menciona en otras cartas.

55 Ençeçinada: seca como la cecina. Es frecuente emplear expresiones propias de la comida para referirse a las cartas que han tardado mucho tiempo en llegar y que, por tanto, son viejas en su información; vid. María Montáñez Matilla, El correo en la España de los Austrias, Madrid, CSIC, 1953, pp. 91-97 para estos asuntos prácticos.
} 
Gregorio o que se enbiase la memoria que a vuestra alteça se le concedió, porque importaría mucho. Porque el que embió el Gran Duque era para un quadro de lapidaçio (sic) chico, para la cabeçera de la cama, no se puede ganar, sino solo el Rey. Y estotro que V. alteza embió no avía de traer este capítulo, sino que le ganasen todos quantos reçasen en él, porque le daría su Magestad a El Escurial.

Ya tengo gana de yr a ver a vuestra alteza y también mi muger os desea conoçer, y diçe que no saldría d'España por ninguna manera si no fuese por amor de vos. Mas por ser tan peligrosa la yda, si no era enviar una galera por mí y por mi muger, para asegurar mi onra, yo no partiera, por los peligros que ay por el camino. Es tanto el amor que os tengo y lo que mereçéis que por amor de vos me pondría a qualquiera cosa que conviniese a vuestro serviçio. Y acordándome quando os tomáis las manos vos y el Gran Duque, así lo hacemos yo y mi muger, y le digo: “Así hace el Gran Duque a la Gran Duquesa quando están comiendo", y que tan bien le saven los buenos bocados como a mí. Y es cosa de ver los amores que nos acemos y dicimos [sic]. Y mi hijo paréceme en todo, que la otra madrugada le tuve en mi cama y se me cagó en ella y biénele de casta, que asta en esto ubo de pareçer a mí. No digáis que no os doy quenta de todo. También dice mi muger y yo lo digo que me enviéis unos salsichones de Florençia y unos quesos, porque mi muger tiene gana de comer cosas de por allá. Y quiero que me hagáis una caja y se la deis a Baltasar Suárez, mi amigo, que él me la enviará, porque siendo cosa vuestra nos sabrá muy bien. Yo creo que la semana que biene me boy a Monzón, porque su Magestad me á embiado que me parta. Plega a Dios que me dé salud para que os pueda servir a vos y al Gran Duque, porque ya os doy palabra que antrambos [sic] a dos me devéis arto y porque me hallo ocupado. No digo más, sino que me tenéis el coraçón robado, que mi muger me pide celos de lo mucho que os quiero que es $\mathrm{ss}^{\mathrm{a}} / \mathrm{ff}^{\mathrm{a}}$. Y de Madrid a 14 de nobiembre de 1585 años.

Vuestro verdadero amigo para lo que me mandáredes,

Gonçalo de Liaño 56

A medida que ha ido consolidándose la confianza entre Bianca Capello y Gonzalo de Liaño, las peticiones de éste se han concretado en dinero o en gestiones ante su marido, a quien le pide que aplaque o que convenza de su inocencia en cierto negocio ${ }^{57}$. Como la corte es un espacio de poder y relaciones que pueden a su vez ser

\footnotetext{
${ }^{56} \mathrm{ASF}, \mathrm{MP}, 5940$ f. 748.

${ }^{57}$ Así en carta de 5 de julio de 1584 le dice; "Bien entiendo que el Gran Duque tendrá cólera conmigo, que le conosco su condición. Y pues crió Dios a V. A. tan clementíssima y piedosa [sic] por hacer merced a todo el mundo y bien a su Gonçalico, que la fama de V. A. en esta corte y en todo el mundo es de altíssima reyna, es raçón no tener cólera conmigo, sino que V. A. se sirva aplacar al serenísimo Duque, mi señor, si alguna tiene contra di me [sic], pues al fin al fin soy su Gonçalico y su hijo y para conmigo, que soy tan del servicio de esa serenísima casa, no es menester tener cólera, sino mandarme líberamente y si no fuere obediente a sus mandamientos, quíteme la cabeça, que la vida, aunque fueran cien vidas, daré por bien empleada" (ASF, MP 5937, f. 51).
} 
el medio idóneo para establecer lazos nuevos o abrirse puertas con cierta facilidad y al igual que hiciera desde Roma para buscar un acceso a Giacomo Boncompagno y a Luigi d'Este, ahora que necesita acercarse a la reina de Francia, envía un memorial a la Gran Duquesa (no a su esposo) y le pide que sea ella quien le dé acceso hasta Luisa de Lorena, la esposa de Enrique III. Estas gestiones estaban indicadas desde la corte española y a pesar de no conocer su contenido exacto, se podrían enmarcar dentro de los sucesos en torno a la firma en Joinville, ese mismo año, de un tratado secreto entre España y los príncipes católicos de la Casa de Lorena para apoyar un heredero católico al trono.

Sereníssima señora,

Yo me hallo muy triste de que no tengo cartas de V.A., sabiendo lo que yo la amo y la quiero, y siempre suspiro por bos. Y tengo raçón de suspirar, pues no nació muger de tanta discreción ny balor como tenéis la fama por todo el mundo. Pugliera ${ }^{58}$ Dios que yo pudiera yr dentro en esta carta para ber ese rostro angelical, porque no á cosa en el mundo que sea bastante para quitarme la malancolía y malos umores que tengo, sino solo veros. Y dichoso fue el Gran Duque en saver tan bien escoger y enplearse. La marquesa del Balle os escrive una carta, y es berdadera amiga vuestra, porque en occasiones que tocan a vuestro servicio se á señalado ${ }^{59}$. Yo me boy para Balencia, porque ya estoy mejor - bendito sea Dios - y para hacer diligencia para qu'el Rey me enbíe por allá, que lo deseo mucho por vuestro contento.

Mi heredero le é tenido muy malo y mi muger os desea conocer. Ya sabéis que yo soy muy amigo de mi honra y ansí, aunque baya a Ytalia, no pienso llebarla comigo, por los peligros que corren por allá. Si V. A. no me manda otra cossa, aora quiero suplicaros un negocio que hagáis por mí, por ser cossa que dicen que me darán quince ducados y sé que lo podéis hacer con escrevir una carta a la reyna de Francia. Y también quiero que se lo pidáis al Gran Duque que scriva a su embajador, para que hable en este particular a la reyna. Y el memorial yrá dentro en esta carta de V. A., por donde se entenderá el negocio que pido.

Y no os olvidéis de mí y de que soy buestros amores a lo divino, con licencia del gran duque, porque aora no me puede ofender con el puñal, porque'stoy lejos. Y porque os riáys, daréys mis vesamanos aquella criada que se llama Catalina Velena, quando en Pisa me dio con la almohadilla de los alfileles [sic] y la aporee [sic], y V.A. me tenía miedo aquella noche. $\mathrm{Y}$ porque me hallo cansado y con gana de comer un par de perdices, que mi muger me mata que acave y me pide celos de los amores que escrivo a V. A., no digo

\footnotetext{
58 Lee publiera.

59 Lee sellalado.
} 
más, sino que Nuestro Señor guarde a V. A. muchos años y en estado acreciente como yo deseo. De Madrid y diciembre a 14 de 85.

Vuestro berdadero amigo para lo que me mandaredes,

Gonçalo de Liaño ${ }^{60}$

Al bufón no se le permite flaquear, solo el cometido de alegrar a su amo justifica una existencia en la que sus penas deben ceder ante la función. Por eso, aunque se encuentra muy mal, con una enfermedad que arrastra largo tiempo ${ }^{61}$, sus cartas a Bianca Capello no pasan de mencionarlo, si acaso lo hacen.

Es tanto el contento que tengo con la carta de vuestra alteza en quererme honrar en este christianismo. Como el Prínçipe de Mantua enbió a convidar el baptismo de su hijo al Rey nuestro señor y al rey de Françia y al Emperador, tanbién yo inbié a convidar por el mismo orden, por venir mi hijo de gran linaje como yo vengo: su Magestad es mi compadre y la Enperatriz mi madrina. Mande vuestra alteza se hagan luminarias y fiestas por el infante que me ha nacido, que naçió día de Nuestra Señora a las diez ${ }^{62}$. Y cierto que pareçe tan goloso como yo, porque tomó unos lamedores ${ }^{63}$ muy bien, meneando los ojos como cosa que le dava mucho gusto. Reçibo a V. alteza por mi comadre y mi muger me manda que escriba a vuestra alteza que le vesa las manos por la honra que V. alteza le haçe en quererla V. alteza honrar.

Y el negocio que V. alteza me encomendó sobre la Marquesa del Valle no le tengo olbidado, que ya he hablado a su Magestad y le di un memorial hecho de mi cabeza, y le hablé solo y dije marabillas del valor de V. alteza. Su Magestad me dijo que respondería al memorial y que acudiese a don Juan Idiáquez, que es con quien hemos de tratar estas cosas. Tengo esperança en Dios seré yo el enbajador destos negocios. Aý enbío a V. alteza la copia del memorial que di a su Magestad, supplico a V. alteza que le vea y no dé relación a nadie hasta que se haga, que las cosas de veras tanbién las sé yo callar. Remítome a una carta que yo escribo a Luis de Ovara.

De los salchichones y quesos más o menos, parézeme que V. alteza se ha olbidado cómo me lo prometio en una carta los días pasados, y mi muger me da la me sa la vaya [?].

\footnotetext{
${ }^{60}$ ASF, MP 5938, f. 231 r. Entre f. 231v. y f. 232r. hay un recorte, en letra distinta de la carta, donde se lee una única línea: "El dixe a V. alteza se queda, porque el majadero del dueño no acudido".

${ }^{61}$ Arandica, en carta de 28 de junio de 1586 desde El Escorial (ASF, MP 781, f. 603) dice: "mi amigo Gonzalillo á estado muy al cabo y está todavía muy malo. Su Magestad á mandado a dos dotores miren por él y se le tenga cuenta de todo aquello que fuere de menester. Es hombre que no es desagradezido y tienen vuestras altezas serenísimas aquí un buen solizitador en él, porque todo aquello que es en servizio desa casa lo aze como muy hombre de bien".

${ }_{62}$ Todo este párrafo es sin duda burlesco, lo mismo que en otras cartas bufonescas donde el loco afirma su alto linaje para provocar la risa de su itnerlocutor, por eso no es posible aceptar la afirmación de S. Salort y S. Kubersky-Piredda, art. cit., 2006, p. 660, basándose en esta cita de que Liaño procedía de una familia noble.

${ }^{63}$ Lamedores: medicamento que se toma lamiéndolo.
} 
Supplico a V. alteza que cumpla su palabra y porque deseo verme en camino para ir a V. alteza, plega a Dios se cumpla mi deseo. $\mathrm{Y}$ acuérdese vuestra alteza de que se me pague toda la resta que se me deve y se dé a Baltasar Suárez. Y porque no tengo más que avisar, sino Dios me conserve en gracia de V. alteza y del Gran Duque, mi señor; y al Marquesito con la buena Peregrina. Fecha en Madrid oy 19 de agosto de 1586.

Vuestro Gonzalo que hos desea más ver que no escrebiros,

Gonçalo de Liaño ${ }^{64}$

A comienzos de 1587 escribió una carta desde Milán, pero en marzo está de vuelta en Madrid y pasará allí casi el resto del año. En julio le anuncia a la Gran Duquesa que ya está en perspectiva un viaje próximo y el rey le ha dado una joya de regalo, pero su viaje no será directo:

También me encarga su Magestad negoçios para Turín, adonde forçosamente havré de yr antes y entretenerme çerca de un mes, pero puede estar segura V.A. que me dare toda la priesa posible para gozar del Poggio y de la buena conversaçion que me han dicho que havrá allá. Y al tiempo que yo partiere, que será con mucha brevedadd, escriviré otra con algún particular de más

Efectivamente, cumple su promesa y en agosto le envía las últimas noticias antes de iniciar el viaje.

Sereníssima señora

Esta es para abisar a V.A. cómo el lunes me despedí de su Magestad en San Lorenço, que fue muy sentida la mi partida, y me dixo de palabra amorosas que dijese a V. A. y presentase esta joia de parte suia; mas no puedo deçir nada hasta que me bea con V. A. Mándame su Magestad que pase por Turín y que bea a la Infanta y le dé un despacho que me á dado, con un presente que yo llebo, y en acabando de haçer mi embajada abisaré a V. A. desde el camino donde yo estubiere. Y quando entrare en el estado del Gran Duque es menester que me embíe el maiordomo con todo el aderezo de comida, como suelen haçer a otros embajadores, y V. A. me á de resçibir como a embajador y darme silla y honrrarme, que yo daré a V. A. la mano derecha, que no lo hago con otros. Y enbía orden a Génoba que como me desenbarque, me bisiten de parte de V. A., y abisarme cómo me á de tratar, y si se me á de haçer el reçebimiento que tengo dicho; y haçer las amistades entre mí y el Gran Duque, y que como yo llegue allá yo daré satisfaçión de todas las cosas que me á encomendado.

Mi muger echa a V. A. maldiciones, que diçe que á sido la ocasión de partirme yo de aquí y siente mucho mi partida. El embajador diçe que dará 4 reales a mi muger cada día para

${ }^{64}$ ASF, M. P. , 5943, f. 4 r.-v. 
que coma mientras yo estubiere por allá, aunque á dicho que más ganaba yo por acá mi muger. Naçióme una hija a çinco de agosto y la enbío a criar a una aldea con otro hijo que tengo allá, pues me debéis tanto que más de quatro tienen enbidia de lo que yo echo [sic] por vos. Y esto lo diré yo quando esté por allá. Que mandéis, como esta carta llegare, escribir luego al embajador que está acá que se pague çinquenta reales más para pagar las amas, porque mi mujer esté con vos bien, que las maldiçiones las torne en bendiçiones. Yo entiendo que se enbiará alguna cosa a vuestro hijo el Marquesito de parte del Rey o del Prínçipe, que será alguna espada de precio, porque me lo á dicho un ministro prinçipal oy. Y porque yo me parto la semana que biene para Italia, no digo más. De Madrid y de agosto a 20 de 1587.

Vuestro berdadero amigo para lo que me mandaredes,

Gonçalo de Liaño ${ }^{65}$

Esta fue la última carta de Gonzalo de Liaño que recibió la Gran Duquesa. El día 10 de octubre se difunde la noticia de que el Gran Duque está enfermo, luego también su esposa. El 19 de ese mes moría Francisco I y al día siguiente Bianca Capello. Pocos días antes habían hecho las paces con el cardenal Fernando de Medici, hermano y futuro Gran Duque, con quien habían estado desde el 25 de septiembre pasando unos días en la villa de Poggio Caggiano. Los rumores se extendieron diciendo que ambos o al menos ella, siempre una advenediza para su cuñado y bajo sospecha de haber engañado al Gran Duque haciendo pasar al "Marquesito" por hijo suyo, había sido envenenada66. En el archivo no hay cartas de Liaño durante unos meses, pero en mayo de 1588 Gonzalo escribe desde Mantua al nuevo Gran Duque, Fernando I, para apaciguar su ira por el retraso en la llegada informándole de algunas gestiones y de que está indispuesto. A la vez, siguiendo su costumbre, le pide a Leonora den Medici, duquesa de Mantua, que escriba por su parte una carta donde efectivamente ella confirma que dada la salud de Gonzalo no debe partir. Aun así el 5 de junio está en Venecia y desde allí Gonzalo vuelve a escribir al Gran Duque asegurando que se verán pronto. En el mes de septiembre de ese 1588, un tal fray Diego Pardo se dirige al Gran Duque diciendo:

\footnotetext{
${ }^{65}$ ASF, MP, 5945, f. 467r-v.

$66 \mathrm{Vid}$. G. E. Saltini, art. cit., a partir de las minutas de secretarios y relaciones de embajadores, sostiene que esa sospecha no corría entre los mejor informados y la da por falsa.
} 
Y porque podría ser aún no acordarse vuestra alteza de quien esta escribe, digo que soy aquel fraile de Sant Francisco, tío de la muger de Gonzalo Liaño, que esté en el zielo, de quien traía cartas para el marido para que él me faboreziera con vuestra Alteza y parézeme que murió antes que acá llegase ${ }^{67}$.

Ya fuera por su enfermedad o porque no estaban los tiempos para bromas, en estas últimas cartas no recurre al humor. Conocía al antiguo Cardenal y nuevo Gran Duque, había hecho gestiones para él ${ }^{68}$, pero basta con breves misivas de contacto e información con las que apaciguar su posible impaciencia y tenerle al tanto de sus movimientos. La posibilidad de usar la burla no la establecía el bufón, sino su amo, porque al fin y al cabo se trataba de un modo de comunicación que implicaba a ambas partes y en la que el poderoso marcaba las pautas. Gonzalo de Liaño, hombre de mundo, hábil negociador y gestor, entiende la risa como una forma de franquearse el paso al corazón de las personas, pero ésta solo es posible cuando encuentra un interlocutor dispuesto a participar de lo festivo, a compartirlo y alentarlo. En este aspecto Bianca Capello actuó como una cómplice necesaria que le permitió desplegar su talento en las cartas, a las que respondía probablemente con un tono similar69. Por ello, estas cartas fueron escritas por el bufón, pero no dejan de ser a la vez una muestra del espíritu de la Gran Duquesa, del ambiente de su corte y en parte obra suya al alentar esta escritura que hoy nos sigue divirtiendo y nos deja atisbar una perspectiva más viva y humana de la historia.

\footnotetext{
${ }^{67} \mathrm{ASF}, \mathrm{MP}, 800$, f. 240.

${ }^{68}$ Una carta de 7 de julio de 1582 (ASF, MP, 756, f. 63) que está entre las destinadas al Gran Duque, es mucho más probable que estuviera dirigida al Cardenal, porque trata al destinatario de "ilustrísima" y menciona al Gran Duque como un tercero. Esta carta tiene un tono jocoso y le pide permiso para salir de Florencia e ir a pescar.

${ }^{69}$ Son muchas las veces en que Liaño menciona haber recibido cartas; en una de 3 de febrero de 1596, le dice: "dízeme su Magestad que si el Gran Duque entendiera lo que m'escrivís de amores en vuestra carta, que si yo estuviera allá, que corriera peligro", ASF, MP, 5938, f. 629-630.
} 